Int. J. Curr. Res. Med. Sci. (2017). 3(7): 160-166

\begin{tabular}{|c|c|c|c|}
\hline & International Journal of Current Research in \\
Medical Sciences & \\
ISSN: 2454-5716 & \\
P-ISJN: A4372-3064, E -ISJN:A4372-3061 \\
WWW.ijcrims.com
\end{tabular}

\title{
Assessment of sleep quality among first year medical students of KAiMS, Karwar: a cross-sectional study
}

\author{
Dr. Prasad BK MD-Physiology \\ Associate Professor, Dept of Physiology \\ Karwar Institute of Medical Sciences, Karwar, Karnataka, India \\ Email:docprasadbk@gmail.com \\ Dr. Clevin Rashmi Rebello MD-Physiology \\ Assistant Professor, Dept of Physiology \\ Karwar Institute of Medical Sciences, Karwar, Karnataka, India \\ Email:drcrashmi@yahoo.com \\ Dr. Preethi G Hegde \\ Tutor, Department of Physiology, Karwar Institute of Medical Sciences. \\ Karwar,Karnataka -581301 \\ Email:drghegde@gmail.com \\ Corresponding author: Dr. Clevin Rashmi Rebello, MD-Physiology \\ Assistant Professor, Dept of Physiology \\ Karwar Institute of Medical Sciences, Karwar, Karnataka, India - 581301 \\ Email:drcrashmi@yahoo.com
}

\begin{abstract}
Background: Adequate amount of sleep is required for the optimal functioning of human body.

Aims and objectives: To study the quality of sleep among newly joined I MBBS students using Pittsburgh Sleep Quality Index (PSQI).

Materials and methods: A cross-sectional study was conducted in Physiology Department at Karwar Institute of Medical Sciences, Karwar. Out of 150 students 125 participated voluntarily. Their socio-demographic profile and sleep quality during the last one month was assessed using PSQI.

Results : $16(12.8 \%)$ reported fairly bad/very bad sleep quality, 17(13.6\%) reported more than $30 \mathrm{~min}, 56(44.8 \%)$ reported sleep duration of less than or equal to $6 \mathrm{hr}$. Habitual sleep efficiency is relatively better with decreased sleep duration. 21(16.8\%) reported sleep disturbance once or twice a week and $1(0.8 \%)$ reported three or more times a week, 8(6.4\%) participants were using sleep medication, 22(17.6\%) reported 3 or $>3$ score for daytime dysfunction. $54.4 \%$ had Global PSQI score 5 and more than 5. Statistically insignificant gender difference in sleep quality was noted.

Conclusion: A high prevalence of sleep disturbance among newly joined medical students can be reduced by proper planning, counseling and orienting the students towards the course.
\end{abstract}

Keywords: sleep disturbance, PSQI 


\section{Introduction}

Newly joined medical students appear to be at increased risk for sleep deprivation as they are under constant stress because of transition from family life to professional life, academic stress, and peer pressure to perform well. These new demands instigate changes in their sleep in the form of late night study and also consuming stimulants to stay awake at night. These habits would impair theirphysical, cognitive and emotional functions, which indirectly can affect the community in the form of road traffic accidents and medical errors (Mirghani HO et al., 2015).The prevalence of sleep disorders among the general population is estimated as $15-35 \%$ in contrast with medical studentsas 30\% (Ohayon MM and Gullieminault C, 2006; Foley DJ et al., 1995).

The normal human body requires seven hrs of night sleep and eight to nine hours of daily sleep (Rasekhi S et al., 2016). Whereas the sleep wake cycle of medical students is characterized by insufficient sleep duration, delayed onset of sleep and napping episode during the day time (Ng EP et al., 2009; Sweileh WM et al., 2011).There are various causes for sleep deprivation like obstruction sleep apnoea, depression, chronic sleep deprivation,n arcolepsy, cataplexy (Plicher JJ and Walter AS, 1997; Pagel JF, 2009).Inspite of all these various factors contributing to sleep deprivation the relationship between sleep deprivation and academic performance of a medical student has been a debatable issue. Earlier studies have reported disturbed sleep among medical interns, residents (Basner $\mathrm{M}$ et al., 2017).We intended to know the prevalence of sleep quality among newly joined I MBBS students.

\section{Aims and Objectives:}

To assess quality of sleep among newly joined I MBBS students using Pittsburgh Sleep Quality Index (PSQI).

\section{Materials and Methods}

After obtaining a prior approval from the institutional ethical committee, a cross-sectional study was conducted in the department of Physiology at Karwar Institute of Medical Sciences, Karwar, Karnataka, India, on newly joined first year MBBS students. The intention of the study was explained to students and was assured that their identity will not be disclosed. The students who volunteered to participate were included in the study. The students who were not interested were excluded. Informed written consent of the participants was taken.

The volunteered participants of the study were asked to assemble in the Lecture hall on one day morning in the month of October 2016. The proforma consisting of socio demographic profile and Pittsburgh sleep quality index questionnaire was distributed among them. The contents of the questionnaire were explained by one of the author to all the participants in common. They were asked to mark appropriately for each question in the questionnaire. Queries regarding the different aspects in the questionnaire of each participant were addressed separately by rest of the authors. Adequate time as required by the participants was given for completing the questionnaire and later it was collected.

Pittsburgh sleep quality index (PSQI) (Buysse DJ et al., 1989)

Pittsburgh sleep quality is a self-rated questionnaire consisting of nineteen questions is used to assess seven components of sleep subjective sleep quality, sleep latency, sleep duration, habitual sleep efficiency, sleep disturbance, and usage of sleep medication during the last one month. Each question of the questionnaire carries score from $0-3$, with 0 being the highest and 3 being the lowest score. The seven component scores are then added to get a global PSQI score in the range of 0-21. A global score equal to or more than 5 indicates poor sleep quality in the past month. PSQI is reliable with Cronbach's $\alpha$ 0.83.

The data was compiled in Microsoft excel and appropriate statistical tests like percentage of prevalence of poor sleep quality and Student's unpaired $t$ test for comparison between males and females were applied using Microsoft excel 2010. 


\section{Results}

Out of 150 I MBBS students 125 volunteered to participate in the study of which 56 were male and 69 were female. The average hours spent in bed was $6 \mathrm{hr} 30 \mathrm{~min}$ and the average sleep duration was $6 \mathrm{hr}$.

Table 1. Subjective sleep quality among participants

\begin{tabular}{|c|c|c|c|}
\hline Subjective sleep quality & Rating & Participants & $\%$ \\
\hline Very good & 0 & 35 & 27.1 \\
\hline fairly good & 1 & 74 & 59.2 \\
\hline fairly bad & 2 & 13 & 10.4 \\
\hline very bad & 3 & 3 & 2.4 \\
\hline
\end{tabular}

\section{$\mathrm{N}=\mathbf{1 2 5}$}

$16(12.8 \%)$ participants reported fairly bad/very bad sleep quality and rest reported good sleep quality.

Table 2. Sleep latency in participants

\begin{tabular}{|c|c|c|c|}
\hline Sleep latency & Rating & Participants & $\%$ \\
\hline$<15 \mathrm{~min}$ & 0 & 64 & 51.2 \\
\hline $16-30 \mathrm{~min}$ & 1 & 44 & 35.2 \\
\hline $31-60 \mathrm{~min}$ & 2 & 15 & 12 \\
\hline$>60 \mathrm{~min}$ & 3 & 2 & 1.6 \\
\hline $\mathbf{N}=\mathbf{1 2 5}$ & & & \\
\hline
\end{tabular}

17(13.6\%) participants reported more than $30 \mathrm{~min}$ of which $2(1.6 \%)$ reported more than $60 \mathrm{~min}$.

Table 3. Sleep duration in participants

\begin{tabular}{|c|c|c|c|}
\hline Sleep duration & Rating & Participants & \% \\
\hline$>7 \mathrm{hr}$ & 0 & 27 & 21.6 \\
\hline $6 \mathrm{hr}-7 \mathrm{hr}$ & 1 & 42 & 33.6 \\
\hline $5 \mathrm{hr}-6 \mathrm{hr}$ & 2 & 44 & 35.2 \\
\hline$<5 \mathrm{hr}$ & 3 & 12 & 9.6 \\
\hline
\end{tabular}

$$
\mathrm{N}=125
$$

$56(44.8 \%)$ reported sleep duration of less than or equal to $6 \mathrm{hr}$ of which $12(9.6 \%)$ reported less than $5 \mathrm{hr}$. 
Int. J. Curr. Res. Med. Sci. (2017). 3(7): 160-166

Table 4. Habitual sleep efficiency in participants

\begin{tabular}{|c|c|c|c|}
\hline Habitual sleep efficiency & Rating & Participants & $\%$ \\
\hline$>85 \%$ & 0 & 123 & 98.4 \\
\hline $75-84 \%$ & 1 & 2 & 1.6 \\
\hline $65-74 \%$ & 2 & 0 & 0 \\
\hline$<65 \%$ & 3 & 0 & 0 \\
\hline
\end{tabular}

Habitual sleep efficiency is relatively better with decreased sleep duration.

Table 5. Reporting of sleep disturbance in participants

\begin{tabular}{|l|c|c|c|}
\hline Sleep disturbances & Rating & Participants & \% \\
\hline Not during the past month & 0 & 11 & 8.8 \\
\hline Less than once a week & 1 & 92 & 73.6 \\
\hline Once or twice a week & 2 & 21 & 16.8 \\
\hline Three or more times a week & 3 & 1 & 0.8 \\
\hline
\end{tabular}

$\mathbf{N}=125$

$21(16.8 \%)$ reported sleep disturbance once or twice a week and $1(0.8 \%)$ reported three or more times a week.

Table 6. Reporting of usage of sleep medication

\begin{tabular}{|c|c|c|c|}
\hline Usage of sleep medication & Rating & Participants & $\%$ \\
\hline Not during the past month & 0 & 117 & 93.6 \\
\hline Less than once a week & 1 & 6 & 4.8 \\
\hline Once or twice a week & 2 & 1 & 0.8 \\
\hline Three or more times a week & 3 & 1 & 0.8 \\
\hline
\end{tabular}

$\mathbf{N}=125$

$8(6.4 \%)$ participants were using sleep medication

Table 7. Reporting of daytime dysfunction in participants

\begin{tabular}{|c|c|c|c|}
\hline Daytime dysfunction scaling & Rating & Participants & \% \\
\hline 0 & 0 & 34 & 27.2 \\
\hline 1 and 2 & 1 & 69 & 55.2 \\
\hline 3 and 4 & 2 & 17 & 13.6 \\
\hline 5 and 6 & 3 & 5 & 4 \\
\hline
\end{tabular}

$\mathbf{N}=125$ 
$22(17.6 \%)$ reported 3 or $>3$ score for daytime

dysfunction.

Table 8. Global PSQI score in participants

\begin{tabular}{|c|c|c|}
\hline Global PSQI score & Participants & \% \\
\hline$\geq 5$ & 68 & 54.4 \\
\hline $\mathbf{N}=\mathbf{1 2 5}$ & 57 & 45.6 \\
\hline
\end{tabular}

54.4\% had Global PSQI score 5 and more than 5

Table 9. Gender difference in Global PSQI score in participants

\begin{tabular}{|c|c|c|c|c|}
\hline $\begin{array}{c}\text { Global PSQI } \\
\text { score }\end{array}$ & $\begin{array}{c}\text { Male } \\
(\mathbf{N = 6 9 )}\end{array}$ & $\%$ & $\begin{array}{c}\text { Female } \\
(\mathbf{N = 5 6})\end{array}$ & $\%$ \\
\hline$\geq 5$ & 39 & 56.5 & 29 & 51.7 \\
\hline$<5$ & 30 & 43.4 & 27 & 48.2 \\
\hline
\end{tabular}

Student's unpaired t test $\mathrm{p}=0.19$

There seem to be gender difference in sleep quality but statistically insignificant.

\section{Discussion}

Medical curriculum is voluminous in comparison with other profession. The profession demands knowledge of each subject in depth and to be updated. Hence students are exposed to such demand as they move from Class XII to professional college. With the voluminous curriculum students feel stressed. Along with it, inclusions of classmates and seniors as hostel mates after moving away from home and family members seem to add as stress.

Few students cope up the stress at the earliest and few experience some psychological changes within. Because of the stress some may experience sleep disturbance which would affect their general health and performance. The present study aimed to note the sleep quality of newly joined IMBBS students.

With the demand of daily reading of the subjects to keep in pace with the lectures taught in class and peer pressure to perform well in exams, the students work hard to understand the new terminologies they are exposed to. In this regard the time spent in bed is reduced and also the time slept. Along with academic stress, feeling of loneliness in the new environment makes them sleep deprived. This will affect their general health.

When compared to general population and other professional students sleep quality of medical students is highly affected (Mirghani HO et al., 2015; Rasekhi S et al., 2016; Araujo MFM et al., 2013; Brick CA et al., 2010). Various components of sleep are affected. Sleep latency gets prolonged. Duration of sleep gets reduced (Brick CA et al., 2010).Habitual sleep efficiency gets affected. ${ }^{[1]}$ Sleep disturbance with frequent awakening during night is noted (Surani AA et al., 2015).Because of disturbed sleep they tend to use sleep medications as prescribed (Satti GM et al., 2015). Few may even fall asleep during daytime and lack concentration in the lectures (Al-Zahrani JM et al., 2016).Students tend to use mobile phone with internet late-night to cope up with stress (Brick CA et al., 2010). 
There could be gender difference in deterioration of sleep quality as evidenced in this study though statistically insignificant. But earlier studies have noted sleep disorder to be higher among female students (Rasekhi S et al., 2016; Keshavarz Akhlaghi AA and Ghalebandi MF, 2009).This has to be confirmed over larger group study.

\section{Conclusion}

This study revealed a higher prevalence of sleep disorder among I MBBS students with insignificant gender difference. Proper counseling to students regarding the curriculum before entering the professional course is highly required. Spending leisure time in exercise and yoga would help them to relax their minds and improve their sleep.

\section{Acknowledgements}

The authors acknowledge the participants and the Staff of Physiology Dept, KAiMS, Karwar, for their kind support and encouragement.

Conflict of interest: There is no conflict of interest among authors.

\section{References}

1. Mirghani HO, Mohammed OS, Almurtadha YM, Ahmed MS. Good sleep quality is associated with better academic performance among Sudanese medical students. BMC research notes 2015; 8(1): 706.

2. OhayonMM, GullieminaultC. Epidemiology of sleep disorders. Sleep a comphrehensive hand book. Hoboken,NewJersey:Wiley-Liss; 2006.

3. Foley DJ, Monjan AA, Brown SL, Simonsick EM, Wallace RB, Blazer DG. Sleep complaints among elderly persons: an epidemiologic study of three communities. Sleep 1995; 18(6): 425-32.

4. Rasekhi S, Ashouri FP, Pirouzan A. Effects of Sleep Quality on the Academic Performance of Undergraduate Medical Students. Health Scope 2016; 5(3): e316-41.
5. Ng EP, Ng DK, Chan CH. Sleep duration, wake/sleep symptoms, and academic performance in Hong Kong secondary school children. Sleep and Breathing. 2009; 13(4): 357-67.

6. Sweileh WM, Ali IA, Sawalha AF, Abu-Taha AS, Sa'ed HZ, Al-Jabi SW. Sleep habits and sleep problems among Palestinian students. Child and adolescent psychiatry and mental health. 2011; 5(1): 25.

7. Plicher JJ, Walter AS. How sleep deprivation affect psychological variables related to college students cognitive performance. J Am Coll Heal 1997; 46: 121-6.

8. Pagel JF. Excessive daytime sleepiness. AM Fan Physician 2009; 97: 391-6.

9. Basner M, Dinges DF, Shea JA, Small DS, Zhu J, Norton L, Ecker AJ, Novak C, Bellini LM, Volpp KG. Sleep and alertness in medical interns and residents: an observational study on the role of extended shifts. Sleep 2017; 40(4): zsx027

10. Buysse DJ, Reynolds CF, Monk TH, Berman SR, Kupfer DJ. The Pittsburgh Sleep Quality Index: a new instrument for psychiatric practice and research. Psychiatry Research 1989; 28(2):193-213.

11. Araujo MFM, Lima ACS, Alencar AMPG, Araujo TM, Fragoso LVC, Danasceno MMC. Text Context Nursing, Florianopolis 2013: 22(2); 352-360.

12. Brick CA, Seely DL, Palermo TM. Association between sleep hygiene and sleep quality in medical students. Behavioral sleep medicine 2010; 8(2): 113-21.

13. Surani AA, Zahid S, Surani A, Ali S, Mubeen M, Khan RH. Sleep quality among medical students of Karachi, Pakistan. J Pak Med Assoc 2015; 65(4): 380-2.

14. Satti GM, Alsaaid HF, Nabil NM, Saeed AA, AlHamdan N, El-bakri NK. The prevalence of sleep problems and its impact on sleep quality and academic performance. Merit Research Journal 2015; 3(2): 126-31.

15. Al-Zahrani JM, Aldossari KK, Abdulmajeed I, Al-Ghamdi SH, Al-Shamrani AM, AlQahtani NS. Daytime Sleepiness and Academic Performance among Medical Students. Health Science Journal 2016; 10(3): 13.1-5. 
16. KeshavarzAkhlaghi AA, Ghalebandi MF. Sleep quality and its correlation with general health in pre-university students of Karaj, Iran. Iranian Journal of Psychiatry and Behavioral Sciences 2009; 3(1): 44-9.

\begin{tabular}{|c|c|}
\hline \multicolumn{2}{|c|}{ Access this Article in Online } \\
\hline \multirow{2}{*}{ 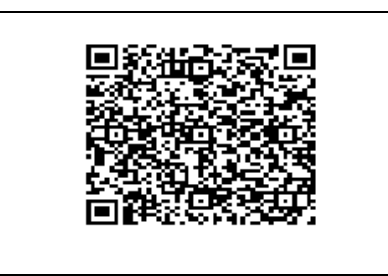 } & $\begin{array}{l}\text { Website: } \\
\text { www.ijcrims.com }\end{array}$ \\
\hline & \multirow[t]{2}{*}{$\begin{array}{l}\text { Subject: } \\
\text { Physiology }\end{array}$} \\
\hline Quick Response Code & \\
\hline
\end{tabular}

How to cite this article:

Prasad BK , Clevin Rashmi Rebello, Preethi G Hegde. (2017). Assessment of sleep quality among first year medical students of KAiMS, Karwar: a cross-sectional study. Int. J. Curr. Res. Med. Sci. 3(7): 160166.

DOI: http://dx.doi.org/10.22192/ijcrms.2017.03.07.023 